\title{
Encefalitis por virus de Saint Louis: A propósito de un caso
} Saint Louis encephalitis: Case report

\author{
Dra. Carolina Carballo ${ }^{a}$ Dra. Magdalena Cabana ${ }^{a}$, Dra. Francisca Ledezma ${ }^{a}$, Dra. Carolina Pascual ${ }^{a}$, \\ Dra. Claudia Cazess ${ }^{a}$ Dra. Alicia Mistchenko y Dr. Eduardo López ${ }^{a}$
}

\begin{abstract}
RESUMEN
La encefalitis por el virus de Saint Louis es una enfermedad que se transmite a través de mosquitos de la especie Culex. En Argentina, se registran casos esporádicos, habitualmente asintomáticos en niños.

Se presenta el caso de una paciente con manifestaciones clínicas inusuales en edad pediátrica y lesiones en el sistema nervioso central no descritas hasta el momento en la literatura.

Se trata de una niña de 8 años, que consultó por síndrome febril, cambios conductuales, ataxia, clonus y rigidez de nuca. En el líquido cefalorraquídeo, se detectó pleocitosis predominantemente mononuclear. Se realizó una resonancia magnética, que evidenció imágenes de isquemia bitalámica. La infección por virus de Saint Louis se diagnosticó por IgM en el suero y el líquido cefalorraquídeo. La paciente evolucionó de manera favorable. Al momento del egreso hospitalario, persistía con bradipsiquia y alteraciones conductuales y se recuperó definitivamente 45 días después del alta.

Palabras clave: encefalitis de St Louis, virus de la encefalitis de St Louis.
\end{abstract}

\begin{abstract}
Saint Louis encephalitis is transmitted by Culex mosquitoes. In Argentina sporadic cases are registered. Symptomatic illness is unusual in children.

We present a case of meningoencephalitis caused by an uncommon viral infection. The clinical signs and symptoms are unusual for pediatric patients and the bilateral thalamic compromise showed on magnetic resonance has not been described previously.

An 8-year-old girl consulted due to fever, behavior disorders and ataxia. Clonus and neck stiffness were detected at physical exam. Cerebrospinal fluid revealed mononuclear leukocytosis; bilateral ischemic compromise was observed in thalamus by magnetic resonance. Saint Louis virus was confirmed by serology: serum and cerebrospinal fluid $\operatorname{IgM}$ were positive during the acute phase of the disease and serum IgG was positive four weeks later. Most of the signs and symptoms of the disease were resolved, however mild behavior disorders were observed as acute sequelae up to 45 days after hospital discharge.

Key words: encephalitis, St Louis, St Louis encephalitis virus.
\end{abstract}

http:/ /dx.doi.org/10.5546/aap.2016.e268

a. Servicio de Infectología Infantil. Hospital de Niños Ricardo Gutiérrez. Ciudad de Buenos Aires.

Correspondencia: Dra. Carolina Carballo,

Carolinacarballo1981@gmail.com

Financiamiento: Ninguno.

Conflicto de intereses: Ninguno que declarar.

Recibido: 4-1-2016

Aceptado: 1-2-2016

\section{INTRODUCCIÓN}

La encefalitis de Saint Louis es una enfermedad causada por el virus de Saint Louis, arbovirus perteneciente a la familia Flaviviridae. Se transmite a través de mosquitos de la especie Culex. Las aves migratorias actúan como reservorio y los seres humanos, como huéspedes terminales.

Menos del 1\% de las infecciones son sintomáticas. Los adultos mayores de 60 años son el grupo de riesgo. Para el diagnóstico, es fundamental la clínica y los estudios virológicos. El tratamiento es de sostén y no existe tratamiento específico.

En Argentina, habitualmente, se presentan casos esporádicos, en especial a fin del verano y principio del otoño.

\section{CASO CLÍNICO}

Paciente de 8 años, oriunda de un área rural de Merlo, provincia de Buenos Aires, sin antecedentes patológicos para destacar. Consultó a fin del verano, en el mes de marzo, por presentar síndrome febril de 4 días de evolución, mala actitud al momento de la ingesta oral y dolor lumbar, y se agregaron, en las últimas horas, cambios en la conducta.

Al ingresar, se constató deshidratación moderada, sensorio alternante con tendencia al sueño, desorientación temporoespacial, risa inmotivada, rigidez de nuca, envaramiento, clonus agotable y ataxia. Con diagnóstico presuntivo de meningoencefalitis aguda, se realizaron estudios de laboratorio, con función renal y hepática dentro de los límites normales. En el hemograma, leucocitos: $11200 / \mathrm{mm}^{3}$ (cayados: $8 \%$; segmentados: $70 \%$; linfocitos: $20 \%$; monocitos: $2 \%$ ); hemoglobina: $11,9 \mathrm{~g} / \mathrm{dl}$; plaquetas: $170000 /$ $\mathrm{mm}^{3}$. La tomografía axial computada (TAC) del sistema nervioso central (SNC) y el fondo de ojo fueron normales. Se realizó una punción lumbar, con citoquímico en el líquido cefalorraquídeo (LCR), y se evidenciaron proteínas: $98 \mathrm{mg}$ / dl; glucosa: $51 \mathrm{mg} / \mathrm{dl}$ (glucemia: $100 \mathrm{mg} / \mathrm{dl}$ ); células: 305 (65\% mononucleares). Se inició un tratamiento empírico con $220 \mathrm{mg} / \mathrm{kg} /$ día de cefotaxime y $30 \mathrm{mg} / \mathrm{kg} /$ día de aciclovir. Se solicitó un electroencefalograma, que se informó 
desorganizado, con hipovoltaje, lentificado, con predominio en el hemisferio izquierdo.

A las $72 \mathrm{~h}$ del ingreso, con resultados de hemocultivos negativos y LCR negativo para gérmenes comunes, se suspendió el tratamiento con cefotaxime. Se recibió reacción en cadena de polimerasa (polymerase chain reaction; PCR, por sus siglas en inglés) para virus del herpes simple (herpes simplex virus; HSV, por sus siglas en inglés) 1 y 2 , y para enterovirus, que fue negativa. Se realizó una resonancia magnética nuclear (RMN) de cerebro, que informó una alteración de la señal en la región anteromedial de ambos tálamos, relativamente simétrica, hipointensa en T1 (Figura 1) e hiperintensa en T2 (Figura 2) y FLAIR. Los hallazgos se interpretaron como de causa isquémica. La secuencia de difusión mostró restricción bilateral y el mapa ADC (coeficiente de difusión aparente, por sus siglas en inglés), relativa isointensidad. Por persistir febril, con alteración de la conducta, se decidió realizar una nueva punción lumbar. En el citoquímico en LCR, proteínas: $66 \mathrm{mg} / \mathrm{dl}$; glucosa: $49 \mathrm{mg}$ / dl (glucemia: $132 \mathrm{mg} / \mathrm{dl}$ ); células: 100 (94\% mononucleares). Se ingresó una nueva muestra para PCR de HSV 1 y 2, que fue negativa, y PCR para Streptococcus pneumoniae, PCR para

FiguRA 1. Resonancia magnética nuclear en T1: imágenes hipointensas en la región anteromedial de ambos tálamos

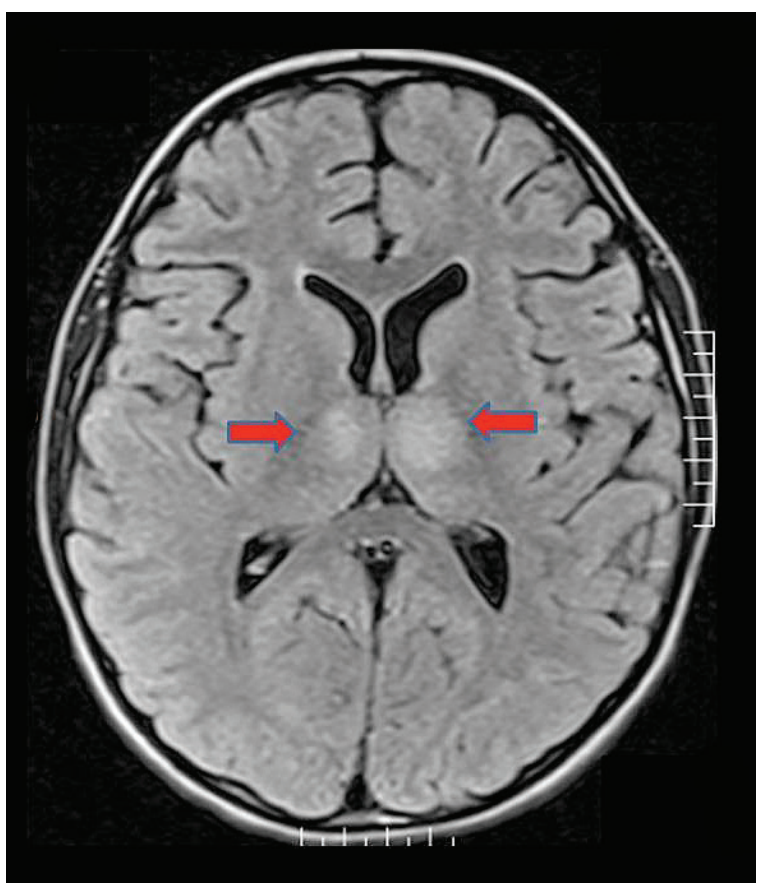

M. tuberculosis y enterovirus, con resultados negativos. Se suspendió el tratamiento con aciclovir. Se solicitó IgM para arbovirus en LCR, que fue positiva para virus de Saint Louis. Al momento del diagnóstico, se solicitaron estudios serológicos: IgM fue positiva e IgG, negativa. Al mes, se repitió IgG sérica, con resultado positivo. Las determinaciones fueron realizadas por inmunofluorescencia.

La paciente evolucionó favorablemente, afebril, y se constató, a los 10 días de su ingreso, la recuperación total de la marcha, el sensorio y la conexión temporoespacial. Se realizó un electroencefalograma con trazado normal. Al momento del egreso hospitalario, persistía con bradipsiquia, alteraciones conductuales y pérdida de la memoria. Se observó una recuperación total de dichos aspectos clínicos a los 45 días del egreso.

\section{DISCUSIÓN}

La encefalitis de Saint Louis es una enfermedad transmitida por el virus de Saint Louis, arbovirus perteneciente a la familia Flaviviridae. ${ }^{1,2}$ Fue descrito por primera vez en 1933, en Saint Louis, Missouri, Estados Unidos. En dicha ocasión, causó 220 muertes.

FIGURA 2. Resonancia magnética nuclear en T2: imágenes hiperintensas en la región anteromedial de ambos tálamos

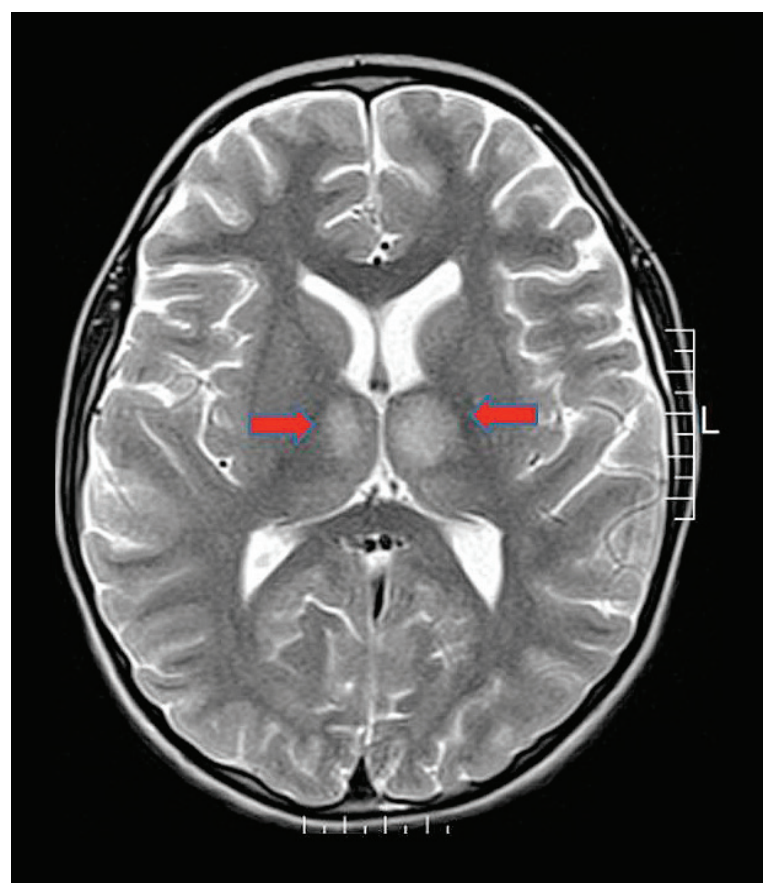


Se distribuye en el continente americano y es endémico en Estados Unidos, donde evoluciona con brotes periódicos, habitualmente cada 10 años, y presenta una incidencia media de 35 casos anuales. ${ }^{1,3}$ En el resto del continente americano, los casos son esporádicos, aunque se han registrado brotes aislados.

En Argentina, se describió el primer caso de encefalitis de Saint Louis en 1963. Por lo general, se han presentado como casos esporádicos. Excepcionalmente, en el año 2005, se detectó un brote en la provincia de Córdoba, con 47 casos confirmados, de los cuales 9 pacientes fallecieron. En el año 2010, se registró el primer brote en la provincia de Buenos Aires, con 13 casos confirmados. ${ }^{4}$ Habitualmente, los casos se producen durante el fin del verano y el principio del otoño. Nuestra paciente se enfermó en marzo.

El reservorio del virus se encuentra en las aves silvestres y de corral, que amplifican el virus, no se enferman y generan inmunidad. ${ }^{1,5}$ Se transmite al hombre a través de mosquitos de la especie Culex, más frecuentemente el Culex pipiens, infectados por el virus de Saint Louis. ${ }^{1,5}$ Los seres humanos actúan como huéspedes terminales; es decir, se contagian por la picadura del mosquito infectado, generan inmunidad y no amplifican el virus, por lo cual no pueden transmitirlo. ${ }^{1,5}$

En cuanto a la patogenia, el virus se reproduce en el sitio de inoculación y genera una viremia primaria, habitualmente neutralizada por el sistema retículo-endotelial. Si esto no ocurre, continúa la replicación viral y produce una viremia secundaria, que puede afectar al SNC. ${ }^{6}$

Presenta un período de incubación de 5 a 15 días. La mayor parte de las infecciones son asintomáticas. En los brotes, la tasa de infección sintomática/asintomática es del orden de 1/800 en niños y $1 / 85$ en adultos mayores de 60 años; estos últimos son el grupo de mayor riesgo., ${ }^{1,7}$

En los casos sintomáticos, se registra un pródromo de síndrome febril y cefalea, que evoluciona a meningoencefalitis solo en el 1\% de los casos.

El compromiso de pares craneales y la ataxia son poco frecuentes. ${ }^{8}$ Es por esto por lo que la forma de presentación de la paciente, dado su grupo etario, no fue la habitual.

Para el diagnóstico de encefalitis de Saint Louis, es fundamental la clínica y el aislamiento viral. Los datos de laboratorio, LCR, electroencefalograma e imágenes del SNC son inespecíficos. Suele existir leucocitosis predominantemente linfocitaria en el hemograma y pleocitosis predominantemente mononuclear en el LCR, como se detectó en la paciente presentada.

No se hallaron, hasta el momento, registros, en la bibliografía, de necrosis bilateral de tálamos secundaria al virus de Saint Louis. ${ }^{9}$

Para el aislamiento viral, puede realizarse PCR para virus de Saint Louis en sangre o LCR, habitualmente presente los primeros cinco días del inicio del cuadro clínico, o bien serología viral (IgM e IgG), presentes, por lo general, a partir del séptimo día de enfermedad.

Se establece como caso confirmado de encefalitis de Saint Louis ${ }^{1,7}$ la enfermedad febril asociada a manifestaciones neurológicas y, al menos, uno de los siguientes criterios de laboratorio:

1. Aislamiento viral o demostración del genoma viral en tejido, sangre o LCR.

2. IgM específica en LCR.

3. Seroconversión por técnica de neutralización en muestras pareadas de suero o LCR.

La paciente presentó clínica compatible, IgM positiva en LCR y suero. Al mes, se constató la seroconversión de $\operatorname{IgG}$ en suero para virus de Saint Louis.

El tratamiento consta de medidas de sostén; no existe tratamiento específico. ${ }^{1,7}$ Los enfermos no requieren aislamiento, ya que no existe contagio de persona a persona.

Respecto del pronóstico, se ha descrito una mortalidad del 5\%-15\%. Puede dejar secuelas neurológicas en el $20 \%$ de los casos, que varían desde pérdida de la memoria o bradipsiquia hasta convulsiones y retraso motor. ${ }^{1,8}$

En nuestra paciente, se constataron conductas atípicas, pérdida de la memoria y bradipsiquia, que persistieron durante el seguimiento. Se recuperó totalmente a los 45 días después del alta.

La prevención de la enfermedad se basa en el control del vector (con medidas ambientales y de concientización social), junto con el cuidado personal (por medio del uso de repelentes, mosquiteros y ropa adecuada al exponerse al vector). ${ }^{1,7}$

\section{REFERENCIAS}

1. Centers for Disease Control and Prevention. Guidelines for arbovirus surveillance programs in the United States. Fort Collins, Colorado: Centers for Disease Control and Prevention; 1993. [Acceso: 1 de febrero de 2016]. Disponible en: http:/ / www.cdc.gov/ncezid/dvbd/pdf/ arboguid_508.pdf.

2. Halperin JJ. Encephalitis: Diagnosis and Treatment. New York: Informa Healthcare; 2008.

3. Day JF. Predicting St. Louis encephalitis virus epidemics: 
lessons from recent, and not so recent, outbreaks. Annu Rev Entomol 2001;46:111-38.

4. Seijo A, Morales A, Poustis G, Romer Y, et al. Brote de encefalitis de San Luis en el área metropolitana Buenos Aires. Medicina (B Aires) 2011;71(3):211-7.

5. Day JF, Stark LM. Transmission patterns of St. Louis encephalitis and eastern equine encephalitis viruses in Florida: 1978-1993. J Med Entomol 1996;33(1):132-9.

6. White MG, Carter NW, Rector FC, Seldin DW, et al. Pathophysiology of epidemic St. Louis encephalitis. I. Inappropriate secretion of antidiuretic hormone. II. Pituitary-adrenal function. 3 Cerebral blood flow and metabolism. Ann Intern Med 1969;71(4):691-702.

7. Argentina. Ministerio de Salud de la Nación. Alertas epidemiológicos. Alertas 2010 [Internet]. [Acceso: 1 de febrerode2016]. Disponible en: http://msal.gob.ar/index. $\mathrm{php} /$ home/funciones/alertas-epidemiologicos.

8. Sejvar JJ, Bode AV, Curiel M, Marfin AA. Post-infectious encephalomyelitis associated with St. Louis encephalitis virus infection. Neurology 2004;63(9):1719-21.

9. Beattie GC, Glaser CA, Sheriff H, Messenger S, et al. Encephalitis with thalamic and basal ganglia abnormalities: etiologies, neuroimaging, and potential role of respiratory viruses. Clin Infect Dis 2013;56(6):825-32. 